\title{
Hollow viscus injuries: predictors of outcome and role of diagnostic delay
}

\author{
This article was published in the following Dove Press journal: \\ Therapeutics and Clinical Risk Management \\ 23 August 2017 \\ Number of times this article has been viewed
}

\author{
Andrea Mingoli ${ }^{1,2}$ \\ Marco La Torre ${ }^{1,2}$ \\ Gioia Brachini',2 \\ Gianluca Costa ${ }^{3}$ \\ Genoveffa Balducci ${ }^{3}$ \\ Barbara Frezza ${ }^{3}$ \\ Giovanna Sgarzini ${ }^{4}$ \\ Bruno Cirillo ${ }^{1,2}$ \\ 'Emergency Department, Policlinico \\ Umberto I, Sapienza University of \\ Rome, Rome, Italy; ${ }^{2}$ Department \\ of Surgery P Valdoni, Policlinico \\ Umberto I, Sapienza University \\ of Rome, Rome, Italy; ${ }^{3}$ Surgical \\ Department of Clinical Sciences, \\ Biomedical Technologies and \\ Translational Medicine, Sant'Andrea \\ Hospital, Sapienza University of \\ Rome, Rome, Italy; ${ }^{4}$ Department \\ of Surgery, S Giovanni Addolorata \\ Hospital, Rome, Italy
}

Introduction: Hollow viscus injuries (HVIs) are uncommon but potentially catastrophic conditions with high mortality and morbidity rates. The aim of this study was to analyze our 16-year experience with patients undergoing surgery for blunt or penetrating bowel trauma to identify prognostic factors with particular attention to the influence of diagnostic delay on outcome.

Methods: From our multicenter trauma registry, we selected 169 consecutive patients with an HVI, enrolled from 2000 to 2016. Preoperative, intraoperative, and postoperative data were analyzed to assess determinants of mortality, morbidity, and length of stay by univariate and multivariate analysis models.

Results: Overall mortality and morbidity rates were $15.9 \%$ and $36.1 \%$, respectively. The mean length of hospital stay was $23 \pm 7$ days. Morbidity was independently related to an increase of white blood cells $(P=0.01)$, and to delay of treatment $>6$ hours $(P=0.033)$, while Injury Severity Score (ISS) $(P=0.01)$, presence of shock $(P=0.01)$, and a low diastolic arterial pressure registered at emergency room admission $(P=0.02)$ significantly affected postoperative mortality.

Conclusion: There is evidence that patients with clinical signs of shock, low diastolic pressure at admission, and high ISS are at increased risk of postoperative mortality. Leukocytosis and delayed treatment ( $>6$ hours) were independent predictors of postoperative morbidity. More effort should be made to increase the preoperative detection rate of HVI and reduce the delay of treatment.

Keywords: bowel injuries, hollow viscus injuries, abdominal blunt trauma, trauma, traumatic bowel perforation, BIPS

\section{Introduction}

Hollow viscus injuries (HVIs) are uncommon and found in $\sim 1 \%$ of all blunt abdominal trauma patients. ${ }^{1}$ Due to their rarity, experience with this injury is limited and no strong consensus exists in the literature regarding diagnosis and management of bowel injuries. $^{2}$

In penetrating trauma, early abdominal exploration is mandatory in $80 \%$ of cases and HVI diagnosis is prompt and easy. In blunt trauma, the non-operative management of solid organ injury has clearly increased the risk of delayed diagnosis and treatment of bowel lesions. ${ }^{3-7}$ Moreover, clinical and radiological diagnoses of bowel and/or mesenteric injuries are difficult as compared to injuries to other visceral organs, especially in cases of multiple trauma patients with head and spinal cord injuries or with impaired consciousness. ${ }^{8}$

Accordingly, patients with undetected blunt HVI, who might otherwise have been diagnosed at laparotomy, could potentially progress to sepsis, multiple organ failure, and death. In spite of this, several surgeons do not consider the effect of delay in 
diagnosis and operative treatment of HVI significant on prognosis, both in adult and pediatric trauma patients. ${ }^{8,9}$

The purpose of this study was to analyze data on HVIs from a multicenter trauma registry, identify effective prognostic indicators in bowel injuries, and evaluate the effect of diagnostic and operative delay on outcome.

\section{Materials and methods}

\section{Study setting}

Policlinico Umberto I, S. Andrea Hospital, and S. Giovanni Addolorata Hospital are three large tertiary hospitals (Policlinico Umberto I and S. Andrea Hospital are two Sapienza University Hospitals) located in the central and northern urban areas of Rome, serving almost 2,000,000 people, and treating $\sim 50 \%$ of the urban major traumas.

\section{Study design}

From a multi-institutional trauma registry including patient data collected from January 2000 to December 2016, 169 consecutive patients operated on for bowel injuries were retrospectively selected. The research was undertaken according to the Italian Privacy Laws concerning collection, storage, and analysis of private data. A formal Institutional Research Ethics Board (Sapienza University and S. Giovanni Addolorata Hospital) approval was not required because of the noninterventional, retrospective, and anonymous study design; however, a signed consent for the treatment and the analysis of data for scientific purpose was obtained from all patients or relatives either at admission or as soon as they could give it.

Both penetrating and blunt bowel injuries were considered, from the cardio-esophageal junction to the rectum at the level of the peritoneal reflection.

All hospital charts as well as the database analysis were reviewed.

Preoperative variables considered for analysis were:

- Demographic data, cause and mechanism of injury, comorbid conditions, clinical features at emergency room (ER) admission such as systolic and diastolic blood pressure, heart rate, Glasgow Coma Scale (GCS), white blood cell count (WBC), hemoglobin values, clinical abdominal signs, and associated lesions.

- Computed tomography (CT) scan findings at admission, Injury Severity Score (ISS), and the Bowel Injury Prediction Score (BIPS). BIPS is a new predictive score for bowel injuries first introduced by McNutt et al, able to predict the risk of a bowel injury when more than two of the following parameters are present at ER admission: 1) high grade mesenteric injury at admission CT scan,
2) increased WBC $(>17,000), 3)$ abdominal tenderness. High grade mesenteric injury was considered as the presence of a mesenteric contusion or hematoma with associated bowel wall thickening and adjacent inter-loop fluid collection, or an active vascular/oral contrast extravasation, bowel transection or pneumoperitoneum. ${ }^{10}$

- Time from ER arrival to operating room and total elapsed time. Intraoperative data included surgical approach, type of treatment and reconstruction, and associated procedures.

Postoperative data included clinical events and follow-up. Mortality, morbidity, and length of hospital stay (LOS) were also retrieved from the database. Mortality was identified as any death occurring within the first 30 days from trauma or during the entire hospital stay. Morbidity was evaluated according to Clavien-Dindo classification ${ }^{11}$ and Surgical Site Infection (SSI) classification. ${ }^{12}$

The primary endpoint of our study was to assess effective predictors of morbidity/mortality and LOS.

Secondary endpoints were the relationship between diagnostic delays and morbidity, mortality, and LOS in HVI and to assess a validated cut-off time for diagnostic delay able to predict the mortality/morbidity rates.

\section{Statistics}

Statistical analyses were performed using MedCalc for Windows, version 10.2.0.0 (MedCalc Software, MariaKerke, Belgium).

Patient and trauma features were analyzed using means \pm SD for quantitative variables, and using frequencies and percentages for categorical variables. Differences in distribution were calculated using the Student's $t$-test and analysis of variance (ANOVA) test for continuous variables, and chisquare test or Fisher's exact test, depending on the number of cases in each subgroup, for categorical variables.

For multivariate analysis, multiple logistic regression was used, including in the model only the variables found to be significant at univariate analysis.

We used receiver operating characteristic (ROC) curve analysis to determine the best threshold and cut-off values for delay of treatment. Sensitivity, specificity, and positive and negative predictive values were calculated. Statistical significance was conventionally defined as $P<0.05$.

\section{Results}

Patient characteristics are shown in Table 1.

Blunt abdominal trauma was the predominant cause of HVI (81.6\%), and a motor vehicle accident was the most frequent mechanism of trauma. 
Table I Patient characteristics

\begin{tabular}{|c|c|}
\hline Patient characteristics & $N=169$ \\
\hline Mean age (range) & $40(16-82)$ years \\
\hline \multicolumn{2}{|l|}{ Sex } \\
\hline Male & I 34 (79.2\%) \\
\hline Female & $35(20.8 \%)$ \\
\hline \multicolumn{2}{|l|}{ Type of trauma } \\
\hline Blunt & $138(81.6 \%)$ \\
\hline Penetrating & $31(18.4 \%)$ \\
\hline Presence of polytrauma & $68(40.2 \%)$ \\
\hline \multicolumn{2}{|l|}{$\left(\mathrm{nv} 6.0-31.0 \quad 10^{9} / \mathrm{L}\right)$} \\
\hline $\begin{array}{l}\text { Mean hemoglobin value } \\
\text { (nv } 5.0-15.9 \mathrm{gr} / \mathrm{L} \text { ) }\end{array}$ & 10.52 \\
\hline Mean SAP (range) & $12 \mid(50-170) \mathrm{mmHg}$ \\
\hline Mean DAP (range) & $68(40-95) \mathrm{mmHg}$ \\
\hline Mean heart rate (range) & 97 (45-140) bpm \\
\hline Mean GCS (range) & $10.2(3-15)$ \\
\hline Mean AIS abdomen (range) & $3(I-6)$ \\
\hline Mean ISS (range) & $24(3-66)$ \\
\hline Mean BIPS (range) & $1.2(0-3)$ \\
\hline Presence of shock & $19(11.2 \%)$ \\
\hline Mean number of blood transfusions (range) & $2(I-4)$ \\
\hline
\end{tabular}

Abbreviations: SAP, systolic artery pressure; DAP, diastolic artery pressure; GCS, Glasgow Coma Scale; ISS, Injury Severity Score; AIS, abbreviated injury scale; BIPS, bowel injury predictive score; nv, normal value.

A polytrauma (multiple traumatic injuries, and trauma with an ISS >16) was observed in $68(40.2 \%)$ patients, and the association with shock was noted in $11.2 \%$ of cases (Table 2).
Mean GCS was 10.2 (minimum 3 - maximum 15). Mean abdominal/abbreviated injury scale and ISS were 3 (range 1-6) and 24 (range 3-66), respectively (Table 1).

A single bowel or mesenteric injury was observed in 143 (84.6\%) patients; jejunum was the most common bowel tract involved ( $65 \%$ of cases), followed by mesenteric and colonic localization. When multiple bowel traumas were noted, the association of bowel and mesenteric injuries was the most frequent condition.

Jejunal suture or resection was the surgical procedure most commonly performed, and ostomy (ileal or colonic) was necessary in $12(7.1 \%)$ cases.

The mean time to surgery after ER arrival was $12 \pm 8$ hours (5.7 \pm 1.2 hours in penetrating trauma and $13.4 \pm 4.2$ hours in blunt trauma); laparotomy was performed in the first 6,12 , and 24 hours after ER admission in 69.8\%, 76.9\%, and 87.5\% of patients, respectively.

A total of 27 postoperative deaths were observed (mortality rate $15.9 \%)$, with $14(51.8 \%)$ deaths in the first 96 hours and directly related to polytrauma.

The overall morbidity rate was $36.1 \%$ (16 patients); the abdominal surgical related complication rate was $19 \%$, and superficial and medium SSI were the most frequent cause of postoperative morbidity. Pulmonary complications were the most prevalent systemic postoperative complication and occurred in $12 \%$ of cases.

Table 2 Univariate and multivariate analysis showing predictors of postoperative morbidity and mortality considering both penetrating and blunt trauma

\begin{tabular}{|c|c|c|c|c|}
\hline \multirow[t]{2}{*}{ Factor } & \multicolumn{2}{|c|}{$\begin{array}{l}\text { Overall postoperative morbidity } \\
\text { (I69 patients) }\end{array}$} & \multicolumn{2}{|c|}{$\begin{array}{l}\text { Overall postoperative mortality } \\
\text { (I69 patients) }\end{array}$} \\
\hline & $\begin{array}{l}\text { Univariate analysis } \\
P \text {-value }\end{array}$ & $\begin{array}{l}\text { Multivariate analysis } \\
\text { P-value (OR, } 95 \% \mathrm{CI})\end{array}$ & $\begin{array}{l}\text { Univariate analysis } \\
\text { P-value }\end{array}$ & $\begin{array}{l}\text { Multivariate analysis } \\
\text { P-value (OR, } 95 \% \mathrm{CI})\end{array}$ \\
\hline Age & 0.036 & - & 0.489 & - \\
\hline Sex & 0.415 & - & 0.814 & - \\
\hline White blood cell count ( $\left.10^{9} / \mathrm{L}\right)$ & 0.003 & $0.016(2.254,0.5 \mathrm{I} 4$ to I.I26) & 0.635 & - \\
\hline Hemoglobin (gr/L) & 0.134 & - & $<0.001$ & $0.264(0.33 \mathrm{I}, 0.569$ to 2.369$)$ \\
\hline SAP $(\mathrm{mmHg})$ & 0.430 & - & 0.002 & $0.078(1.102,0.885$ to 3.489$)$ \\
\hline $\mathrm{DAP}(\mathrm{mmHg})$ & 0.747 & - & $<0.001$ & 0.029 ( $1.247,0.119$ to 0.844$)$ \\
\hline Heart rate (bpm) & 0.134 & - & 0.001 & $0.224(1.001,0.84 \mathrm{I}$ to I.934) \\
\hline Multiple bowel injury & 0.0009 & $0.412(0.496,0.112$ to 7.283$)$ & 0.715 & - \\
\hline Type of HVI blunt/penetrating & 0.846 & - & 0.449 & - \\
\hline AIS abdomen & 0.826 & - & 0.004 & $0.335(0.148,0.147$ to 9.258$)$ \\
\hline GCS & 0.059 & - & $<0.001$ & $0.367(0.369,0.258$ to 6.159$)$ \\
\hline ISS & 0.017 & $0.463(1.225,0.847$ to 3.489$)$ & $<0.001$ & $0.010(1.489,0.998$ to 2.247$)$ \\
\hline Presence of shock & 0.823 & - & 0.016 & $0.026(1.178,1.258$ to 5.687$)$ \\
\hline Presence of polytrauma & 0.690 & - & 0.080 & - \\
\hline Number of blood transfusions & 0.248 & - & 0.001 & $0.368(0.759,0.854$ to I5.32) \\
\hline Ostomy & 0.591 & - & 0.568 & - \\
\hline Delay of treatment & 0.010 & 0.03 I $(I .94 I, 0.8 I 8$ to $I .4 \mid 4)$ & 0.780 & - \\
\hline 6 hours cut-off & 0.022 & $0.045(1.6 \mid 4,0.752$ to 1.973$)$ & & \\
\hline 12 hours cut-off & 0.049 & - & & \\
\hline 24 hours cut-off & 0.199 & - & & \\
\hline
\end{tabular}

Abbreviations: SAP, systolic artery pressure; DAP, diastolic artery pressure; HVI, hollow viscus injury; AIS, abbreviated injury scale; GCS, Glasgow Coma Scale; ISS, Injury Severity Score. 


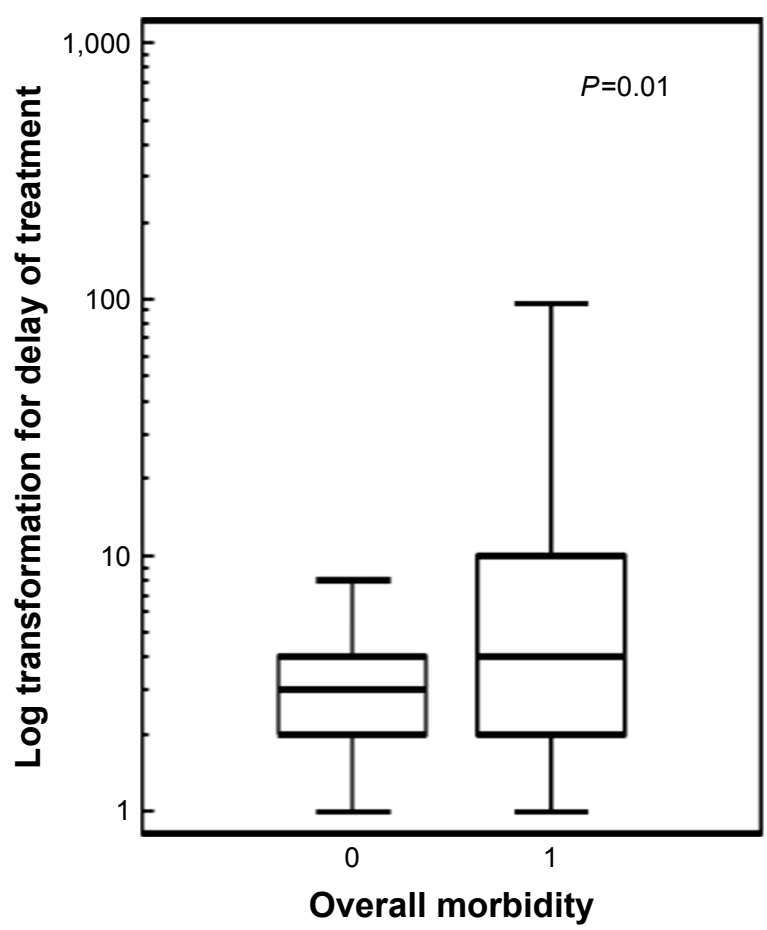

Figure I Delay of treatment and postoperative complications.

The mean LOS was $23 \pm 7$ days (range 1-350).

Prognostic indicators for postoperative mortality after bowel injuries were: $\operatorname{ISS}(P=0.010, \mathrm{OR}=1.489,95 \% \mathrm{CI}=0.998$ to 2.247 ), the presence of shock $(P=0.026, \mathrm{OR}=1.178,95 \%$ $\mathrm{CI}=1.258$ to 5.687 ), and low diastolic pressure registered at ER admission $(P=0.029, \mathrm{OR}=1.247,95 \% \mathrm{CI}=0.119$ to 0.844 ) (Table 2).

Delay of treatment was not a prognostic indicator for postoperative mortality, even after patients who died during the first 24 hours were excluded from the analysis $(P=0.780)$.

The statistical analysis revealed that morbidity was strongly and independently related to an increase of WBC during the initial ER evaluation $(P=0.016$, OR $=2.254$, $95 \% \mathrm{CI}=0.514$ to 1.126$)$, and delay of treatment $>6$ hours $(P=0.031, \mathrm{OR}=1.941,95 \% \mathrm{CI}=0.818$ to 1.414$)$ (Table 2$)$.

When the whole series was considered, the mean delay of diagnosis and treatment for the patients who developed a postoperative complication was $19.1 \pm 3.2$ hours, compared to $6.2 \pm 1.9$ hours for patients who did not present postoperative morbidity (ANOVA test, $P=0.01$ ) (Figure 1, Table 2). The same results were observed when the analysis was limited to blunt trauma patients: the mean delay of diagnosis and treatment for patients who developed a postoperative complication was $22.5 \pm 3.6$ hours, compared to $6.1 \pm 1.4$ hours for patients who did not present postoperative morbidity (ANOVA test, $P=0.007$ ) (Table 3) (Figure 1). In this

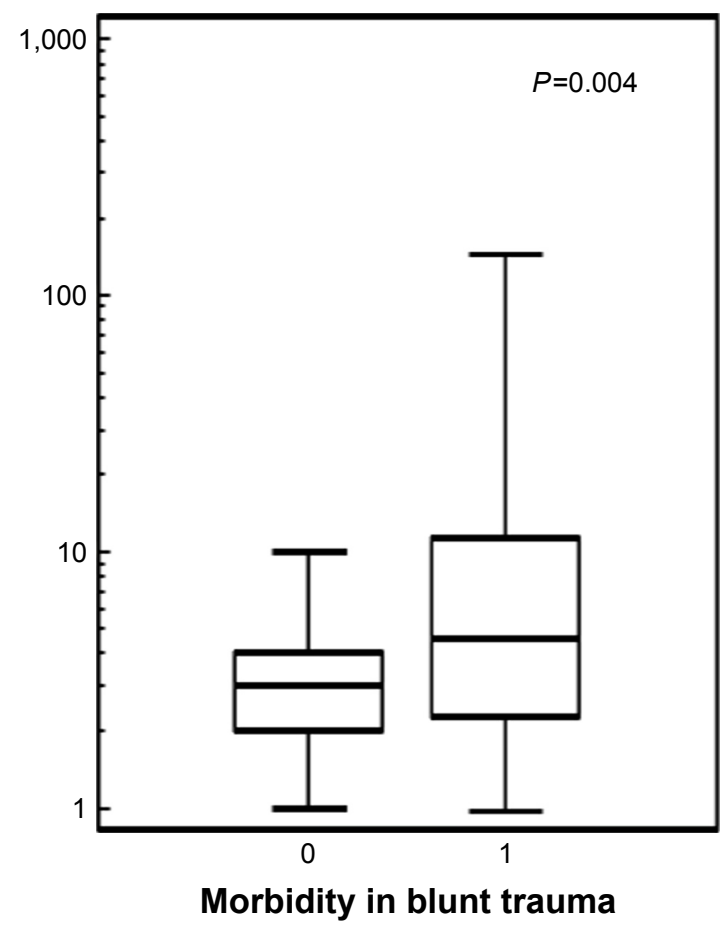

subgroup, BIPS ${ }^{10}$ value was an independent predictor of outcome $(P=0.001$, OR $=0.029,95 \% \mathrm{CI}=1.359$ to 6.158$)$, indicating a significant predictive role in blunt trauma patients (Table 4).

An ROC curve analysis was performed in order to identify predictive cut-off and threshold values in delay of diagnosis and treatment for morbidity. The analysis showed positive predictive values for postoperative morbidity of $73.5 \%$ and $100 \%$ for a delay of treatment of 12 and 24 hours, demonstrating that patients with a bowel injury treated 1 day after ER admission have a $100 \%$ possibility to develop a postoperative complication (Table 5 and Figure 2).

When predictors of treatment delay was analytically studied, a significant correlation was identified with heart rate ( $P=0.036, \mathrm{OR}=2.756,95 \% \mathrm{CI}=0.741$ to 1.159$)$, presence of shock $(P=0.037, \mathrm{OR}=2.547,95 \% \mathrm{CI}=1.176$ to 7.258$)$, type of trauma ( $P=0.045$, $\mathrm{OR}=2.951,95 \% \mathrm{CI}=1.258$ to 6.223$)$, and BIPS ( $P=0.001, \mathrm{OR}=0.029,95 \% \mathrm{CI}=1.359$ to 6.158$)$ (Table 4), indicating that the presence of these parameters strongly suggests a prompt surgical treatment.

\section{Discussion}

Less than $1 \%$ of all patients who present with blunt trauma will have an HVI, and only $0.3 \%$ of all blunt trauma patients will have a perforated small bowel injury. ${ }^{1,13}$ It has been demonstrated that, due to the low incidence of these traumas, 
Table 3 Univariate and multivariate analysis showing predictors of postoperative morbidity and mortality for blunt trauma

\begin{tabular}{|c|c|c|c|c|}
\hline \multirow[t]{2}{*}{ Factor } & \multicolumn{2}{|c|}{$\begin{array}{l}\text { Postoperative morbidity } \\
\text { Blunt trauma ( } 132 \text { patients) }\end{array}$} & \multicolumn{2}{|c|}{$\begin{array}{l}\text { Postoperative mortality } \\
\text { Blunt trauma ( } 132 \text { patients) }\end{array}$} \\
\hline & $\begin{array}{l}\text { Univariate analysis } \\
P \text {-value }\end{array}$ & $\begin{array}{l}\text { Multivariate analysis } \\
P \text {-value }(\mathrm{OR}, 95 \% \mathrm{Cl})\end{array}$ & $\begin{array}{l}\text { Univariate analysis } \\
P \text {-value }\end{array}$ & $\begin{array}{l}\text { Multivariate analysis } \\
P \text {-value }(\mathrm{OR}, 95 \% \mathrm{Cl})\end{array}$ \\
\hline Age & 0.022 & $0.022(\mathrm{I} .745, \mathrm{I} .036$ to $\mathrm{I} .456)$ & 0.478 & - \\
\hline Sex & 0.847 & - & 0.566 & - \\
\hline White blood cell count $\left(10^{9} / \mathrm{L}\right)$ & 0.002 & $0.013(1.657,1.012$ to 2.223$)$ & 0.711 & - \\
\hline Hemoglobin $(g / L)$ & 0.221 & - & $<0.001$ & $0.347(0.458,0.258$ to 1.948$)$ \\
\hline $\mathrm{SAP}(\mathrm{mmHg})$ & 0.430 & - & 0.001 & $0.042(1.668,1.243$ to 1.698$)$ \\
\hline $\mathrm{DAP}(\mathrm{mmHg})$ & 0.617 & - & 0.001 & $0.019(3.125,0.224$ to 0.741$)$ \\
\hline Heart rate $(\mathrm{bpm})$ & 0.474 & - & $<0.001$ & $0.039(2.663,1.225$ to 1.753$)$ \\
\hline Multiple bowel injury & 0.001 & $0.957(0.743,0.158$ to 9.354$)$ & 0.845 & - \\
\hline GCS & 0.468 & - & 0.004 & $0.059(2.354,0.842$ to 1.965$)$ \\
\hline AIS abdomen & 0.337 & - & 0.288 & - \\
\hline ISS & 0.039 & $0.217(0.258,0.789$ to 1.069$)$ & $<0.001$ & $0.019(2.115,1.324$ to I.77I) \\
\hline Presence of shock & 0.038 & $0.986(\mathrm{I} .173,0.457$ to 1.458$)$ & 0.035 & $0.147(1.006,0.899$ to $1.74 I)$ \\
\hline Presence of polytrauma & 0.072 & $0.627(\mathrm{I} . \mathrm{I} 48,0.654$ to $\mathrm{I} .369)$ & 0.654 & - \\
\hline BIPS & 0.005 & $0.04 \mathrm{I}(2.225, \mathrm{I} . \mathrm{I} 45$ to 7.225$)$ & 0.094 & $0.258(0.455,0.776$ to II $.3 \mid 2)$ \\
\hline Number of blood transfusions & 0.813 & - & 0.001 & $0.193(0.74 \mid, 0.489$ to $|8.2| 4)$ \\
\hline Ostomy & 0.419 & - & 0.409 & - \\
\hline Delay of treatment & 0.004 & $0.118(1.078,0.694$ to 1.789$)$ & 0.665 & - \\
\hline 6 hours cut-off & 0.025 & $0.053(1.249,1.158$ to 15.14$)$ & $0.74 I$ & \\
\hline 12 hours cut-off & 0.036 & $0.059(2.159,0.874$ to 14.21$)$ & 0.369 & \\
\hline
\end{tabular}

Abbreviations: SAP, systolic artery pressure; DAP, diastolic artery pressure; GCS, Glasgow Coma Scale; AIS, abbreviated injury scale; ISS, Injury Severity Score; BIPS, bowel injury predictive score.

most trauma centers in the US reported seeing an average of 14 patients with HVI per year, resulting in limited exposure and experience of trauma surgeons who manage fewer than five HVI patients annually, even in large I level trauma centers., ${ }^{1,13}$

Table 4 Univariate and multivariate analysis showing predictors of delay of treatment

\begin{tabular}{|c|c|c|}
\hline Factor & $\begin{array}{l}\text { Univariate } \\
\text { analysis } \\
P \text {-value }\end{array}$ & $\begin{array}{l}\text { Multivariate analysis } \\
P \text {-value }(O R, 95 \% \mathrm{CI})\end{array}$ \\
\hline Age & 0.874 & - \\
\hline Sex & 0.369 & - \\
\hline White blood cell count & 0.258 & - \\
\hline Hemoglobin & 0.741 & - \\
\hline SAP & 0.067 & - \\
\hline DAP & 0.159 & - \\
\hline Heart rate & 0.003 & $0.036(2.756,0.74$ I to I.I59) \\
\hline Bowel injury localization & 0.258 & - \\
\hline Type of trauma $(p / b)$ & 0.001 & $0.045(2.95$ I, I. .258 to 6.223$)$ \\
\hline AIS abdomen & 0.564 & - \\
\hline GCS & 0.654 & - \\
\hline ISS & 0.041 & $0.489(0.95 \mathrm{I}, 0.746$ to I.789) \\
\hline Presence of shock & 0.001 & $0.037(2.547,1.176$ to 7.258$)$ \\
\hline BIPS & 0.001 & $0.029(2.143,1.359$ to 6.158$)$ \\
\hline Presence of polytrauma & 0.789 & - \\
\hline $\begin{array}{l}\text { Number of blood } \\
\text { transfusions }\end{array}$ & 0.456 & - \\
\hline
\end{tabular}

Abbreviations: SAP, systolic artery pressure; DAP, diastolic artery pressure; $\mathrm{p} / \mathrm{b}$, penetrating/blunt; AIS, abbreviated injury scale; GCS, Glasgow Coma Scale; ISS, Injury Severity Score; BIPS, bowel injury predictive score.
This reduced expertise of trauma surgeons is associated with the lack of clear international recommendations or established consensus in terms of optimal diagnostic approach. ${ }^{14}$ Diagnostic peritoneal lavage progressively lost clinical application in the emergent setting, and abdominal CT scan often still fails to recognize indirect signs of traumatic bowel perforation. ${ }^{15}$ Nowadays the advent and diffusion of dual-phase multidetector computer tomography with multiplanar reconstruction has improved the diagnostic accuracy of bowel and mesenteric injuries, but the limited experience of radiologists with these uncommon lesions and the concomitant presence of other abdominal organ injuries, still make this radiologic diagnosis challenging. ${ }^{16-19}$

Table 5 Specificity/sensitivity and positive/negative predictive values of different cut-off time values of delay of treatment for morbidity

\begin{tabular}{lllll}
\hline Criterion & $\begin{array}{l}\text { Sensitivity } \\
(\mathbf{9 5 \%} \mathbf{C l})\end{array}$ & $\begin{array}{l}\text { Specificity } \\
(\mathbf{9 5 \%} \mathbf{C l})\end{array}$ & $\begin{array}{l}\text { Positive } \\
\text { predictive } \\
\text { value } \\
(\mathbf{9 5 \%} \mathbf{C l})\end{array}$ & $\begin{array}{l}\text { Negative } \\
\text { predictive } \\
\text { value } \\
(\mathbf{9 5 \%} \mathbf{C l})\end{array}$ \\
\hline$>6$ hours & 42.3 & 79.3 & 77.1 & 63.4 \\
& $(22.19-58.1)$ & $(42.4-91.5)$ & $(52.8-91.7)$ & $(47.6-75.4)$ \\
$>12$ hours & 22.3 & 94.6 & 73.5 & 59.4 \\
& $(10.6-39.4)$ & $(79.5-92.4)$ & $(45.2-95.3)$ & $(46.9-69.1)$ \\
$>24$ hours & 15.71 & 100.00 & 100.0 & 58.6 \\
& $(6.4-22.6)$ & - & $(50.2-100.0)$ & $(42.9-69.3)$ \\
\hline
\end{tabular}




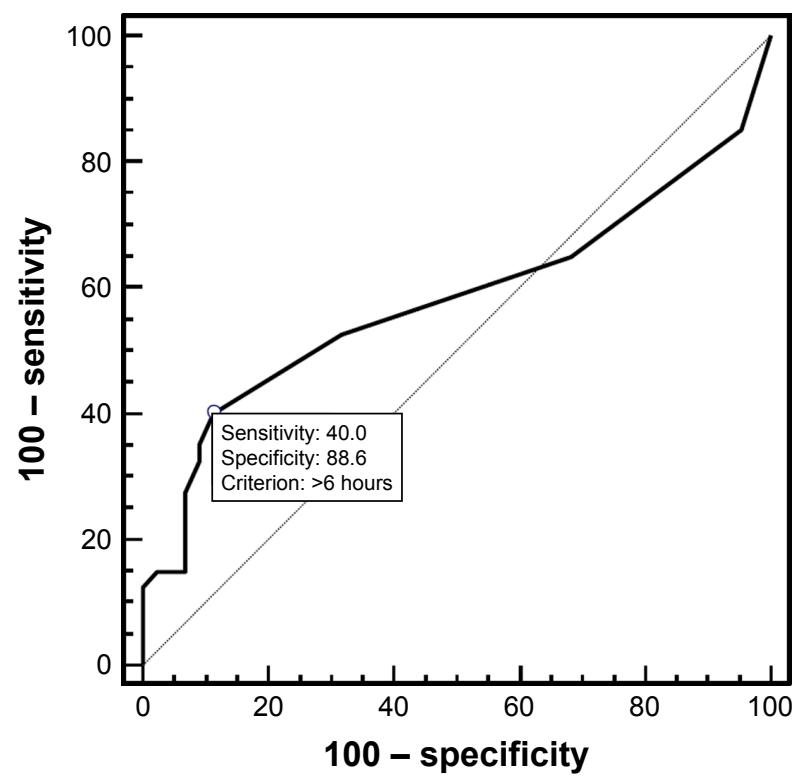

Figure 2 ROC curve for delay of treatment and morbidity. Abbreviation: ROC, receiver operating characteristic.

In addition, the increased prevalence of non-operative management for blunt trauma patients has reduced the rate of urgent laparotomies, thus decreasing the opportunity to treat an unrecognized bowel injury or perforation. ${ }^{3-7}$

In penetrating trauma, abdominal exploration is still commonly performed in $80 \%$ of cases, thus resulting in a significant difference in treatment delay as compared to blunt trauma. ${ }^{20,21}$ In our series, patients with penetrating trauma were surgically treated in a mean time of $5.7 \pm 1.2$ hours compared to patients with blunt trauma who underwent surgery in a mean time of $13.4 \pm 4.2$ hours $(P=0.01$, ANOVA test). Several authors have shown the important diagnostic role of laparoscopy in hemodynamically stable patients with penetrating abdominal trauma: in experienced hands it can determine the integrity of peritoneum and diaphragm, and the presence of bowel and parenchymatous organ injuries. Overall, it can avoid non-therapeutic exploratory laparotomy in up to $70 \%$ of patients and, in selected cases, it can also have a therapeutic role in repairing minor lesions. ${ }^{22,23}$ Also in blunt abdominal trauma, laparoscopy could represent a similar diagnostic option, especially in patients with equivocal clinical and radiologic findings, before doing a laparotomy. However, its role remains undefined because the number of treated patients is small and only few series with promising results have been reported. ${ }^{24,25}$

According to the literature, the ileum is the most common site of bowel injury, followed by mesentery and colon. ${ }^{1,13}$ Perforation can be a common consequence of HVI and massive fecal peritonitis is the most worrisome complication. ${ }^{26}$ Thus, the delay of diagnosis has become a "keyword" in management and treatment of HVI.

Even though past as well as more recent pediatric studies suggest that "short" diagnostic delays have no or little role in determining morbidity and mortality rates, our study highlights the importance of a prompt diagnosis and treatment of bowel injuries in order to reduce morbidity and hospital stay. ${ }^{9}$

Letton and Worrell, in a multicenter study analyzing 358 pediatric patients, demonstrated that any significant statistical difference in terms of morbidity and mortality was found when patients were divided into four groups depending on treatment delay (0-6 hours, 6-12 hours, 12-24 hours, and $>24$ hours). ${ }^{9}$

Despite these findings, and according to other reports, $1,2,8,13$ we demonstrated that treating an HVI within 6 hours from ER admission significantly reduces, at multivariate analysis, the complication rate $(P=0.045, \mathrm{OR}=1.614,95 \% \mathrm{CI}=0.752$ to 1.973), and the delay of treatment became, with the increase of WBC, an independent prognostic factor for postoperative morbidity.

We also demonstrated, through the ROC curve, that a delay in treatment $>24$ hours has a positive predictive value of $100 \%$ for postoperative complications.

Some studies, however, demonstrated that delay of treatment significantly affects postoperative mortality as well; Fakhry et al, enrolling 198 patients from the registries of eight US trauma centers, demonstrated that mortality rates increased from $2 \%$ for patients treated within the first 8 hours from ER admission, to $9.1 \%, 16.7 \%$, and $30.8 \%$ for patients treated after $8-16,16-24$, and $>24$ hours, respectively. ${ }^{2}$

Accordingly, Faria et al observed, in their series of 102 patients with both blunt and penetrating bowel injuries, that all postoperative deaths occurred in patients operated on after the first 24 hours. ${ }^{26}$

Our series failed to demonstrate the influence of the delay of treatment on postoperative mortality; in fact, the statistical analysis outlined the presence of shock, as well as a reduced diastolic artery pressure and ISS as independent prognostic indicators of postoperative mortality.

In order to facilitate the diagnosis of HVI, McNutt et al recently introduced a new effective predictive score for blunt bowel and mesenteric injury. ${ }^{10}$ The authors retrospectively combined three different physical, hematological, and radiological parameters (admission CT scan grade of mesenteric injury, WBC, and abdominal tenderness) in order to 
evaluate their predictive value for the presence of an HVI. They demonstrated that patients with a BIPS of $\geq 2$, were 19 times more likely to have an HVI than patients with a BIPS of less than $2(P<0.001$, OR $=19.2 ; 95 \% \mathrm{CI}=6.78$ to 54.36), showing that the system can be used in combination to create a bowel injury score, with a score of $\geq 2$ strongly associated with HVI. ${ }^{10}$

We specifically analyzed this parameter in our series and demonstrated that patients with a BIPS score $>2$ had a significant probability to develop a postoperative complication $(P=0.029, \mathrm{OR}=2.143,95 \% \mathrm{CI}=1.359$ to 6.158$)$ compared to patients with a BIPS $<2$.

\section{Conclusion}

HVIs are an uncommon finding in abdominal trauma patients. Several prognostic factors have been identified for morbidity and mortality, and among them delay of treatment has been identified as an independent predictor of morbidity, strongly affecting the postoperative course.

More efforts should be directed at increasing the preoperative detection rate of HVIs; new and effective predictive radiological tools in association with physical and hematological parameters (BIPS) seem to increase the diagnostic sensitivity and reduce the delay of treatment to less than 6-12 hours after ER admission.

\section{Author contributions}

All authors contributed toward data analysis, drafting and critically revising the paper, gave final approval of the version to be published, and agree to be accountable for all aspects of the work.

\section{Disclosure}

The authors report no conflicts of interest in this work.

\section{References}

1. Fakhry SM, Watts DD, Luchette FA; EAST Multi-Institutional Hollow Viscus Injury Research Group. Current diagnostic approaches lack sensitivity in the diagnosis of perforated blunt small bowel injury: analysis from 275,557 trauma admissions from the EAST multi-institutional HVI trial. J Trauma. 2003;54(2):295-306.

2. Fakhry SM, Brownstein M, Watts DD, Baker CC, Oller D. Relatively short diagnostic delays ( $<8$ hours) produce morbidity and mortality in blunt small bowel injury: an analysis of time to operative intervention in 198 patients from a multicenter experience. J Trauma. 2000;48(3): $408-414$.

3. Stassen NA, Bhullar I, Cheng JD, et al; Eastern Association for the Surgery of Trauma. Nonoperative management of blunt hepatic injury: an Eastern Association for the Surgery of Trauma practice management guideline. J Trauma Acute Care Surg. 2012;73(5 Suppl 4): S288-S293.
4. Stassen NA, Bhullar I, Cheng JD, et al; Eastern Association for the Surgery of Trauma. Selective nonoperative management of blunt splenic injury: an Eastern Association for the Surgery of Trauma practice management guideline. J Trauma Acute Care Surg. 2012;73(5 Suppl 4): S294-S300.

5. Kerwin AJ, Haut ER, Burns JB, et al; Eastern Association for the Surgery of Trauma Practice Management Guidelines Ad Hoc Committee. The Eastern Association of the Surgery of Trauma approach to practice management guideline development using Grading of Recommendations, Assessment, Development, and Evaluation (GRADE) methodology. J Trauma Acute Care Surg. 2012;73(5 Suppl 4):S283-S287.

6. Diaz JJ Jr, Cullinane DC, Dutton WD, et al. The management of the open abdomen in trauma and emergency general surgery: part 1-damage control. J Trauma. 2010;68(6):1425-1438.

7. Como JJ, Bokhari F, Chiu WC, et al. Practice management guidelines for selective nonoperative management of penetrating abdominal trauma. J Trauma. 2010;68(3):721-733.

8. Brownstein MR, Bunting T, Meyer AA, Fakhry SM. Diagnosis and management of blunt small bowel injury: a survey of the membership of the American Association for the Surgery of Trauma. J Trauma. 2000; 48(3):402-407.

9. Letton RW, Worrell V; APSA Committee on Trauma Blunt Intestinal Injury Study Group. Delay in diagnosis and treatment of blunt intestinal injury does not adversely affect prognosis in the pediatric trauma patient. J Pediatr Surg. 2010;45(1):161-165.

10. McNutt MK, Chinapuvvula NR, Beckmann NM, et al. Early surgical intervention for blunt bowel injury: the Bowel Injury Prediction Score (BIPS). J Trauma Acute Care Surg. 2015;78(1):105-111.

11. Dindo D, Demartines N, Clavien PA. Classification of surgical complications: a new proposal with evaluation in a cohort of 6336 patients and results of a survey. Ann Surg. 2004;240(2):205-213.

12. Horan TC, Gaynes RP, Martone WJ, Jarvis WR, Emori TG. CDC definitions of nosocomial surgical site infections, 1992: a modification of CDC definitions of surgical wound infections. Infect Control Hosp Epidemiol. 1992;13(10):606-608.

13. Watts DD, Fakhry SM; EAST Multi-Institutional Hollow Viscus Injury Research Group. Incidence of hollow viscus injury in blunt trauma: an analysis from 275,557 trauma admissions from the East multiinstitutional trial. J Trauma. 2003;54(2):289-294.

14. Mahmood I, Tawfek Z, Abdelrahman Y, et al. Significance of computed tomography finding of intra-abdominal free fluid without solid organ injury after blunt abdominal trauma: time for laparotomy on demand. World J Surg. 2014;38(6):1411-1415.

15. Iaselli F, Mazzei MA, Firetto C, et al. Bowel and mesenteric injuries from blunt abdominal trauma: a review. Radiol Med. 2015;120(1):21-32.

16. Yu J, Fulcher AS, Turner MA, Cockrell C, Halvorsen RA. Blunt bowel and mesenteric injury: MDCT diagnosis. Abdom Imaging. 2011; 36(1):50-61

17. Khan I, Bew D, Elias DA, Lewis D, Meacock LM. Mechanisms of injury and CT findings in bowel and mesenteric trauma. Clin Radiol. 2014; 69(6):639-647.

18. Landry BA, Patlas MN, Faidi S, Coates A, Nicolaou S. Are we missing traumatic bowel and mesenteric injuries? Can Assoc Radiol J. 2016; 67(4):420-425.

19. Atri M, Hanson JM, Grinblat L, Brofman N, Chughtai T, Tomlinson G. Surgically important bowel and/or mesenteric injury in blunt trauma: accuracy of multidetector CT for evaluation. Radiology. 2008;249(2): 524-533.

20. Nelson R, Singer M. Primary repair for penetrating colon injuries. Cochrane Database Syst Rev. 2003;(3):CD002247.

21. Kirkpatrick AW, Baxter KA, Simons RK, Germann E, Lucas CE, Ledgerwood AM. Intra-abdominal complications after surgical repair of small bowel injuries: an international review. J Trauma. 2003; 55(3):399-406.

22. Ahmed N, Whelan J, Brownlee J, Chari V, Chung R. The contribution of laparoscopy in evaluation of penetrating abdominal wounds. J Am Coll Surg. 2005;201(2):213-216. 
23. Uranues S, Popa DE, Diaconescu B, Schrittwieser R. Laparoscopy in penetrating abdominal trauma. World J Surg. 2015;39(6): $1381-1388$

24. Johnson JJ, Garwe T, Raines AR, et al. The use of laparoscopy in the diagnosis and treatment of blunt and penetrating abdominal injuries: 10-year experience at a level1 trauma center. Am J Surg. 2013;205(3): $317-321$.
25. Lin HF, Chen YD, Lin KL, Wu MC, Wu CY, Chen SC. Laparoscopy decreases the laparotomy rate for hemodynamically stable patients with blunt hollow viscus and mesenteric injuries. Am J Surg. 2015; 210(2):326-333.

26. Faria GR, Almeida AB, Moreira H, Barbosa E, Correia-da-Silva P, Costa-Maia J. Prognostic factors for traumatic bowel injuries: killing time. World J Surg. 2012;36(4):807-812.

\section{Publish your work in this journal}

Therapeutics and Clinical Risk Management is an international, peerreviewed journal of clinical therapeutics and risk management, focusing on concise rapid reporting of clinical studies in all therapeutic areas, outcomes, safety, and programs for the effective, safe, and sustained use of medicines. This journal is indexed on PubMed Central, CAS,
EMBase, Scopus and the Elsevier Bibliographic databases. The manuscript management system is completely online and includes a very quick and fair peer-review system, which is all easy to use. Visit http://www.dovepress.com/testimonials.php to read real quotes from published authors.

Submit your manuscript here: http://www.dovepress.com/therapeutics-and-clinical-risk-management-journal 